\title{
Television viewing and variations in energy intake in adults and children in the USA
}

\author{
Susan B Sisson ${ }^{1, *}$, Stephanie T Broyles ${ }^{2}$, Candace Robledo ${ }^{3}$, Lindsay Boeckman ${ }^{3}$ and \\ Misti Leyva ${ }^{1,4}$ \\ 'Behavioral Nutrition and Physical Activity Laboratory, Department of Nutritional Sciences, University of \\ Oklahoma Health Sciences Center, 1200 N Stonewall Ave, AHB 3068, Oklahoma City, OK 73117-1215, \\ USA: ${ }^{2}$ Pennington Biomedical Research Center, Baton Rouge, LA, USA: ${ }^{3}$ Department of Biostatistics and \\ Epidemiology, University of Oklahoma Health Sciences Center, Oklahoma City, OK, USA: ${ }^{4}$ Clinical Research \\ Center, University of Oklahoma Health Sciences Center, Oklahoma City, OK, USA
}

Submitted 7 June 2011: Accepted 29 September 2011: First published online 9 November 2011

\begin{abstract}
Objective: Examine the association between energy intake and television (TV) viewing in Americans.

Design: Nationally representative, cross-sectional study of 2003-2006 National Health and Nutrition Examination Survey.

Setting: Total energy intake was determined by two $24 \mathrm{~h}$ recalls. TV viewing was reported as low $(\leq 1 \mathrm{~h} / \mathrm{d})$, middle $(2-3 \mathrm{~h} / \mathrm{d})$, and high $(\geq 4 \mathrm{~h} / \mathrm{d})$. Multivariate linear regression models were used to analyse TV viewing and energy intake, adjusted for BMI (percentile for children 2-18 years), age, ethnicity and physical activity.

Subjects: Pre-school children ( $2-5$ years; $n$ 1369), school-age children (6-11 years; $n$ 1759), adolescents ( $12-18$ years; $n$ 3233) and adults ( $\geq 19$ years; $n 7850$ ) in the USA. Results: There was a significant association between TV viewing and energy intake for adolescent girls (high $v$. low: $\beta=195 \cdot 2, P=0 \cdot 03$ ) and men (high $v$. low: $\beta=-113 \cdot 0, P=0 \cdot 02$; middle $v$. low: $\beta=-131 \cdot 1, P=0 \cdot 0002$ ). Mean adjusted energy intake for adolescent girls was $7801 \cdot 0,8088 \cdot 5$ and $8618 \cdot 2 \mathrm{~kJ} / \mathrm{d}$ for low, middle and high TV viewing, respectively. Mean adjusted energy intake for men was $9845 \cdot 9$, $9297 \cdot 2$ and $9372 \cdot 8 \mathrm{~kJ} / \mathrm{d}$ for low, middle and high TV viewing.

Conclusions: TV viewing was associated with energy intake in US children and adults only in 12-18-year-old girls and men. For girls, the high TV viewing category consumed more energy daily $(816 \cdot 3 \mathrm{~kJ}(195 \mathrm{kcal}))$ than the low category. In men, the middle and high TV viewing categories consumed less energy daily $(548 \cdot 4 \mathrm{~kJ}$ (131 kcal) and $473.0 \mathrm{~kJ}(113 \mathrm{kcal})$, respectively) than the low category. Our findings support some, but not all previous research. Future research is needed to explore this complicated relationship with rigorous measures of energy intake and TV viewing.
\end{abstract}

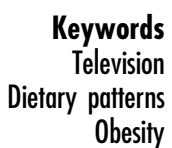

Recently, sedentary behaviour among adults and children has received attention as a public health concern $^{(1-5)}$. Sedentary behaviour is defined as behaviour that does not increase metabolic rate higher than resting and includes sitting $^{(1,4)}$. Sedentary behaviour can be objectively measured through devices worn that measure posture or intensity of activity as well as by self- or proxy-reported time in sedentary behaviours such as sitting for work or transportation, watching television (TV) or playing video games, and computer use for recreation and school work. TV viewing is the most predominant leisure-time sedentary behaviour in children ${ }^{(6-10)}$ and adults ${ }^{(11,12)}$. Higher volumes of sedentary time have been associated with mortality ${ }^{(13,14)}$, cardiometabolic disease $\mathrm{e}^{(15-17)}$ and obesity ${ }^{(18,19)}$ in adults and elevated disease risk ${ }^{(20,21)}$ and overweight and obesity ${ }^{(22-24)}$ in children. Several hypotheses have been proposed to explain the relationship observed between TV viewing and health and obesity status. These hypotheses include that: (i) TV viewing displaces time for physical activity; (ii) resting energy expenditure is lower while watching TV; (iii) TV advertising may prompt viewers to consume high-energy snacks during viewing as well as prompts to consume advertised foods later; and (iv) individuals passively overconsume food while watching TV since they are distracted and ignoring cues of satiety.

Evidence from epidemiological studies ${ }^{(10,25)}$, a time-use study of the after-school period ${ }^{(26)}$ and a recent meta-analysis ${ }^{(23)}$ support the hypothesis that time spent watching TV may be displacing time spent on physical activity since children with high levels of TV viewing concurrently have 
low levels of physical activity, although this relationship has a small effect ${ }^{(23)}$. There is also evidence to support the contrary (i.e. sedentary behaviour does not displace physical activity) ${ }^{(27)}$. An epidemiological study reported no correlation between TV viewing and accelerometermeasured moderate-to-vigorous physical activity $(r=0 \cdot 013$, $P=0 \cdot 58)^{(27)}$. Furthermore, a cross-sectional clinical study using doubly labelled water showed that the relationship between TV viewing and fatness was not mediated by physical activity in children; although children who watched higher amount of TV were significantly less physically active $^{(28)}$. Further, studies supporting the complexity of these behaviours detail that interventions that have sought to reduce TV viewing were unable to demonstrate subsequent increases in physical activity, even though decreases in overall body weight were reported ${ }^{(29,30)}$. Some research has examined whether individuals experience a lowered metabolic rate while viewing $\mathrm{TV}^{(31,32)}$. However, it is generally accepted that metabolic rate is no lower than in any other sedentary pursuit ${ }^{(33)}$. There is evidence that indicates advertisements seen by children while watching TV can impact the brands and types of foods they request ${ }^{(34-36)}$. Moreover, those children who report paying attention to TV commercials had higher odds of requesting (OR $=$ 3.43; 95\% CI $2 \cdot 55,460)$, buying (OR $=2 \cdot 73$; $95 \%$ CI $2 \cdot 17$, $3 \cdot 43)$ and eating snacks while watching TV $(\mathrm{OR}=1 \cdot 60$; $95 \%$ CI $1 \cdot 23,2 \cdot 07)^{(37)}$. Further, cues of satiety have been shown to be disregarded by children ${ }^{(38)}$ and college students $^{(39)}$ while watching TV.

Several studies, detailed in a recent review ${ }^{(40)}$, have examined eating patterns and sedentary behaviours in children and adults. Dietary patterns assessed include snacking, fruit and vegetable consumption, fat intake and total energy intake. While many observational studies support the hypothesis that higher sedentary behaviour is associated with poor dietary quality in children and adults, albeit not necessarily total energy intake, not all studies are in agreement and results vary by age ${ }^{(40)}$. While it is very important to understand the relationship between dietary patterns and TV viewing, excess energy intake has been reported to be a predominant driver of the obesity epidemic ${ }^{(41,42)}$. Eight of eleven $(73 \%)$ studies in children aged $<12$ years indicate that higher sedentary behaviour is associated with higher energy intake. Among children aged 12-18 years, three of nine studies reported a positive association. In adults, five of seven studies (71\%) showed a positive association between sedentary time and energy intake. Total energy intake, which is expected to be directly associated with overweight and obesity status, has been studied less frequently than fruit, vegetable, sweetened beverage and snack food intake. Further investigation into the complex relationship between TV viewing and energy intake is warranted to accurately understand the association of these behaviours and obesity, particularly due to the evidence that supports increased energy intake as a primary contributor to global obesity issues. This is particularly relevant in the USA where $34 \%$ of children and $66 \%$ of adults are overweight or obese $^{(43)}$ and health costs associated with treatment of obesity and its co-morbidities continue to rise ${ }^{(44)}$. The purpose of the present epidemiological study was to conduct an analysis of data obtained from US children and adults to examine the association between energy intake and TV viewing.

\section{Experimental methods}

The present study is a cross-sectional, epidemiological analysis of children and adults using data collected as part of the National Health and Nutrition Examination Survey (NHANES) 2003-2004 and 2005-2006.

\section{Subjects}

NHANES uses a complex, multistage, probability sampling design to select participants who are representative of the US population. The National Center for Health Statistics ethics review board approved the original survey protocols, and informed consent was obtained for all NHANES participants. Data were obtained for adults and children $>2$ years of age who participated in both dietary recall interviews. NHANES participants with missing data on gender, ethnicity (Mexican American, European American, African American, other), height, weight, TV viewing and physical activity were excluded from the present analyses. Height and weight were used to calculate the BMI $\left(\mathrm{kg} / \mathrm{m}^{2}\right)$ of each participant. According to BMI, adults were then classified as underweight $\left(<18.5 \mathrm{~kg} / \mathrm{m}^{2}\right)$, normal weight $\left(18 \cdot 5-24 \cdot 9 \mathrm{~kg} / \mathrm{m}^{2}\right)$, overweight $\left(25 \cdot 0-29 \cdot 9 \mathrm{~kg} / \mathrm{m}^{2}\right)$ or obese $\left(\geq 30 \cdot 0 \mathrm{~kg} / \mathrm{m}^{2}\right)^{(45)}$. For children, BMI percentile based on age and sex was calculated and classifications were as underweight $(<5$ th percentile), normal weight (5th-84th percentile), overweight (85th-94th percentile) and obese $(\geq 95 \text { th percentile })^{(46)}$. Analyses were stratified by age and conducted separately for pre-school children 2-5 years of age, school-age children 6-11 years of age, adolescents $12-18$ years old and adults $\geq 19$ years of age.

\section{Dietary measures}

Data on the outcome of interest, total energy intake $(\mathrm{kJ} / \mathrm{d})$, were obtained from two $24 \mathrm{~h}$ dietary recall interviews conducted by trained technicians. For all analyses, total energy intake from day 1 and day 2 were averaged, a method previously used with national dietary analyses ${ }^{(47)}$. However, each recall day was examined individually in association with TV viewing to determine if there was a difference. A detailed description of the dietary interviews can be found elsewhere ${ }^{(48,49)}$; however, procedures are summarized here. The first $24 \mathrm{~h}$ recall interview was inperson and took place in the mobile examination centre (MEC). The second $24 \mathrm{~h}$ recall interview was conducted via telephone three to ten days following the MEC interview on 
a different day of the week. Serving sizes and food models were present in the MEC for the initial interview. Participants were given a booklet with information on serving size for the follow-up telephone interview. For children aged $2-5$ years, interviews were conducted with the proxy adult who was most knowledgeable about the child's dietary intake, likely a parent. For children aged 6-11 years, interviews were conducted with the child with adult proxy assistance. The US Department of Agriculture's (USDA) Automated Multiple Pass Method, a computerized system, guided the interviewers to prove and collect easily forgotten foods and beverages.

Participants were asked about food consumed in the previous $24 \mathrm{~h}$. In addition, they were asked to compare the day recalled to usual dietary intake (i.e. more than usual, less than usual or usual intake). For pre-school children, $81.9 \%$ and $88.1 \%$ of the recalled days were usual for day 1 and day 2 of the dietary recall interview. For school-aged children, $74 \cdot 2 \%$ and $88 \cdot 2 \%$ of the recalled days were usual. For adolescents, $67 \cdot 2 \%$ and $79 \cdot 1 \%$ of day 1 and day 2 interviews, respectively, were reported as usual dietary intake. For adults, $73.9 \%$ and $79.0 \%$ of day 1 and day 2 interviews, respectively, were reported as usual intakes.

The USDA Food and Nutrient Database for Dietary Studies (FNDSS), version $2 \cdot 0$ (for 2003-2004) and version 3.0 (for 2005-2006; USDA Agricultural Research Service, Beltsville, MD, USA), was used for processing the reported dietary intakes. The FNDDS provides comprehensive information that can be used to code the individual foods and portion sizes reported by participants, and also nutrient values for calculating nutrient intakes.

\section{Television viewing and physical activity measures}

TV and physical activity measures were collected through an interview conducted in the participants' home (ages $2-11$ years and $\geq 16$ years) or the MEC ( $12-15$ years). For children aged 2-11 years, a proxy completed the interview questions.

To assess TV viewing, participants were asked 'Over the past $30 \mathrm{~d}$, on average about how many hours per day did you sit and watch TV or videos?' Possible responses included less than $1 \mathrm{~h}, 1 \mathrm{~h}, 2 \mathrm{~h}, 3 \mathrm{~h}, 4 \mathrm{~h}$ and $5 \mathrm{~h}$ or more, and were collapsed into low ( $\leq 1 \mathrm{~h} / \mathrm{d})$, middle $(2-3 \mathrm{~h} / \mathrm{d})$, and high $(\geq 4 \mathrm{~h} / \mathrm{d})$.

Physical activity for participants $2-11$ years of age was assessed using the single question, 'How many times per week does (child) play or exercise enough to make (him/ her) sweat and breathe hard?' Responses were reported in whole numbers from 0 (never) to 77 . For participants $\geq 12$ years of age, minutes of moderate-to-vigorous physical activity was assessed through a series of questions. These questions asked participants to report whether or not they had participated in vigorous or moderate physical activity for at least $10 \mathrm{~min}$ over the past $30 \mathrm{~d}$. If participants responded 'yes' to engaging in moderate or vigorous physical activity, information on the specific activities and the duration was collected. If participants responded 'no' moderate or vigorous physical activity, daily active time was recorded as zero. If participants responded 'yes', then the individual time spent in each moderate and vigorous activity was summed to provide a total time in activity per day.

\section{Data analysis}

The SAS statistical software package version $\left.9 \cdot 2^{(}\right)$(SAS Institute, Cary, NC, USA) was used for all analyses. Descriptive statistics including means, standard errors and percentages were calculated to summarize population characteristics. Descriptive information has been presented in $\mathrm{kJ}$; however, outcome analyses were conducted using kcal to maintain manageable parameter estimates. Preliminary analyses revealed an interaction between sex and TV viewing and therefore analyses were stratified by sex. Mean daily total energy intake was calculated using least-squared means for each age and sex group adjusted for age in years, BMI (or percentile for children), physical activity and ethnicity. The relationship between TV viewing and daily energy intake was examined by a series of multivariate linear regression models. The first model included TV viewing, BMI (percentile for children aged 2-18 years), age in years and ethnicity. The second model included all variables for model 1 with the addition of either minutes of moderate-to-vigorous physical activity (adolescents and adults) or times per week of hard play (pre-school and school-age children). Appropriate survey analyses and weight variables were used to ensure national representation of the findings.

\section{Results}

Data were examined for outliers in dietary and physical activity measures. A conservative and systematic measure to eliminate outliers in addition to inaccurate data as a result from memory or over- and under-reporting issues ${ }^{(50)}$ was employed and data from participants whose total energy intake fell within the highest and lowest $2 \%$ of the distribution were not included in these analyses. Data were excluded for pre-school children if total energy intake was less than $3424 \cdot 2 \mathrm{~kJ} / \mathrm{d}(n 38)$ or if it exceeded $12884.5 \mathrm{~kJ} / \mathrm{d}$ ( $n$ 16). For school-aged children, participants were removed if total energy intake was less than $4123 \cdot 2 \mathrm{~kJ} / \mathrm{d}$ ( $n$ 33) or if it exceeded $13755 \cdot 2 \mathrm{~kJ} / \mathrm{d}$ ( $n$ 48). For adolescents, participants were removed if total energy intake was less than $3415 \cdot 8 \mathrm{~kJ} / \mathrm{d}$ ( $n$ 61) or exceeded $19000 \cdot 3 \mathrm{~kJ} / \mathrm{d}$ ( $n$ 49). For adults, participants were removed if total energy intake was less than $3466 \cdot 0 \mathrm{~kJ} / \mathrm{d}$ ( $n$ 112) or exceeded $18066 \cdot 8 \mathrm{~kJ} / \mathrm{d}$ ( $n$ 260). Additionally, if daily moderate-tovigorous physical activity exceeded $12 \mathrm{~h}$, those adolescents $(n 8)$ and adults $(n 4)$ were removed (physical activity was assessed differently in younger children). Final analytical 
Table 1 Descriptive characteristics of young children (2-11 years), older children (12-18 years) and adults in analyses examining TV viewing and energy intake, 2003-2006 National Health and Nutrition Examination Survey

\begin{tabular}{|c|c|c|c|c|}
\hline Variable & $\begin{array}{c}\text { Pre-school (2-5 years) } \\
\%\end{array}$ & $\begin{array}{c}\text { School-aged (6-11 years) } \\
\%\end{array}$ & $\begin{array}{c}\text { Adolescents (12-18 years) } \\
\%\end{array}$ & Adults $\underset{\%}{\geq 19}$ years) \\
\hline Sample & $(n$ 1369) & $(n$ 1668) & $(n$ 3233) & $(n 7850)$ \\
\hline \multicolumn{5}{|l|}{ Age (years) } \\
\hline Mean & $3 \cdot 5$ & $8 \cdot 4$ & $15 \cdot 0$ & $46 \cdot 1$ \\
\hline SE & 0.04 & 0.07 & 0.07 & 0.5 \\
\hline \multicolumn{5}{|l|}{$\operatorname{Sex}(\%)$} \\
\hline Male & $52 \cdot 4$ & $51 \cdot 7$ & $51 \cdot 0$ & $46 \cdot 4$ \\
\hline Female & $47 \cdot 6$ & $48 \cdot 3$ & $49 \cdot 0$ & $53 \cdot 6$ \\
\hline \multicolumn{5}{|l|}{ Ethnicity (\%) } \\
\hline Mexican Ámerican & $14 \cdot 8$ & $13 \cdot 6$ & $11 \cdot 6$ & $8 \cdot 0$ \\
\hline European American & $58 \cdot 5$ & $60 \cdot 6$ & $63 \cdot 7$ & $73 \cdot 0$ \\
\hline African American & $15 \cdot 0$ & $14 \cdot 8$ & $14 \cdot 9$ & $11 \cdot 2$ \\
\hline Other & $11 \cdot 7$ & $11 \cdot 0$ & $9 \cdot 7$ & $7 \cdot 8$ \\
\hline \multicolumn{5}{|l|}{ Poverty income ratio (\%) } \\
\hline$<1 \cdot 0$ & $27 \cdot 2$ & $20 \cdot 3$ & $18 \cdot 8$ & $11 \cdot 2$ \\
\hline $1 \cdot 0-2 \cdot 0$ & $24 \cdot 2$ & $24 \cdot 1$ & $20 \cdot 3$ & $19 \cdot 9$ \\
\hline$\geq 2 \cdot 0$ & $48 \cdot 6$ & $55 \cdot 6$ & $60 \cdot 9$ & $68 \cdot 9$ \\
\hline \multicolumn{5}{|c|}{ Obesity classification* (\%) } \\
\hline Underweight & $3 \cdot 1$ & $2 \cdot 6$ & $3 \cdot 3$ & $4 \cdot 7$ \\
\hline Normal weight & $73 \cdot 4$ & $67 \cdot 2$ & $63 \cdot 0$ & $28 \cdot 8$ \\
\hline Overweight & $10 \cdot 7$ & $12 \cdot 2$ & $16 \cdot 1$ & $33 \cdot 6$ \\
\hline Obese & $12 \cdot 8$ & $18 \cdot 0$ & $17 \cdot 6$ & $32 \cdot 9$ \\
\hline \multicolumn{5}{|l|}{ Daily min of MVPAt } \\
\hline Mean & $\mathrm{n} / \mathrm{a}$ & $\mathrm{n} / \mathrm{a}$ & $64 \cdot 4$ & $29 \cdot 4$ \\
\hline SE & $\mathrm{n} / \mathrm{a}$ & $\mathrm{n} / \mathrm{a}$ & $2 \cdot 6$ & 0.9 \\
\hline \multicolumn{5}{|c|}{ Weekly days of hard playt } \\
\hline Mean & $6 \cdot 8$ & $6 \cdot 5$ & $\mathrm{n} / \mathrm{a}$ & $\mathrm{n} / \mathrm{a}$ \\
\hline SE & $0 \cdot 2$ & $0 \cdot 3$ & $\mathrm{n} / \mathrm{a}$ & $\mathrm{n} / \mathrm{a}$ \\
\hline \multicolumn{5}{|l|}{ TV viewing category (\%) } \\
\hline$\leq 1 \mathrm{~h} / \mathrm{d}$ (low) & $39 \cdot 4$ & $34 \cdot 2$ & $38 \cdot 1$ & $33 \cdot 6$ \\
\hline 2-3 h/d (middle) & $46 \cdot 9$ & $48 \cdot \overline{6}$ & $41 \cdot 6$ & $45 \cdot 2$ \\
\hline$\geq 4 \mathrm{~h} / \mathrm{d}$ (high) & $13 \cdot 7$ & $17 \cdot 2$ & $20 \cdot 3$ & $21 \cdot 2$ \\
\hline
\end{tabular}

TV, television; MVPA, moderate-to-vigorous physical activity; n/a, not applicable.

${ }^{*}$ For adults classifications are underweight $<18.5 \mathrm{~kg} / \mathrm{m}^{2}$, normal weight $18 \cdot 5-24 \cdot 9 \mathrm{~kg} / \mathrm{m}^{2}$, overweight $25 \cdot 0-29 \cdot 9 \mathrm{~kg} / \mathrm{m}^{2}$ and obese $\geq 30 \cdot 0 \mathrm{~kg} / \mathrm{m}^{2}$. For children obesity status is based on BMI percentiles for age and sex with underweight $<5$ th percentile, normal weight 5th-84th percentile, overweight 85 th-94th percentile and obese $\geq 95$ th percentile.

tDifferent questions were asked to children aged 12-18 years and adults $v$. children aged 2-11 years. Adolescents and adults were asked about minutes of MVPA in the previous month, which was used to calculate weekly minutes of MVPA. Pre-school and school-aged children's parent proxy was asked about the times per week the child engaged in exercise or play enough to sweat and breathe hard.

sample sizes for the pre-school children, school-aged children, adolescents and adults were $n$ 1369, $n$ 1668, $n$ 3233 , and $n 7850$, respectively.

Descriptive characteristics of each sample can be found in Table 1 . The mean participant age was $3 \cdot 5,8 \cdot 4,15 \cdot 0$ and $46 \cdot 1$ years for pre-school children, school-age children, adolescents and adults, respectively. Females consistently reported lower daily energy intake. In females, the pre-school girls reported $6580 \cdot 8$, school-aged girls reported $7841 \cdot 5$, adolescent girls reported $7925 \cdot 6$ and women reported $7266.4 \mathrm{~kJ} / \mathrm{d}$. In males, the pre-school boys reported $6908 \cdot 0$, school-aged boys reported $8707 \cdot 0$, adolescent boys reported 10089.6 and men reported $9782 \cdot 1 \mathrm{~kJ} / \mathrm{d}$. In both males and females, the $12-18$ years age group reported the highest daily level of energy intake. The percentage of the sample in the high TV viewing category was $13.7 \%$ for pre-school children, $17 \cdot 2 \%$ for school-aged children, $20 \cdot 3 \%$ for adolescents and $21 \cdot 2 \%$ for adults $(P<0 \cdot 0001)$.

Total energy intake by TV viewing category among age and sex categories can be found in Table 2. There was no significant association between TV viewing category and energy intake for any of the age and sex groups, with the exception of the adolescent girls and men (Table 3). These findings were similar for analyses with and without physical activity for both adolescent girls and men. In the adolescent girls, the high TV viewing category consumed more energy daily $(816.3 \mathrm{~kJ}(195 \mathrm{kcal})$ and $820.5 \mathrm{~kJ}$ $(196 \mathrm{kcal}))$ than the low TV viewing category $(P=0 \cdot 03)$ for models with and without physical activity, respectively. Men in both the middle and high TV viewing categories consumed less energy daily than men in the low TV viewing category. For both models with and without physical activity, men in the middle TV viewing category consumed $548.4 \mathrm{~kJ}(131 \mathrm{kcal})$ less $(P=0 \cdot 0002)$; while men in the high TV viewing category consumed $473.0 \mathrm{~kJ}(113 \mathrm{kcal})(P=0.02)$ and $464.7 \mathrm{~kJ}(111 \mathrm{kcal})$ less $(P=0 \cdot 02)$ than men in the low TV viewing category for models with and without physical activity, respectively. These findings are in the direction opposite of what would be expected (i.e. higher energy intake in those with higher TV viewing). 
Table 2 Total adjusted energy intake (kJ/d) for category of TV viewing by age and gender groups, 2003-2006 National Health and Nutrition Examination Survey

\begin{tabular}{|c|c|c|c|c|c|c|}
\hline & \multicolumn{2}{|c|}{$\operatorname{Low}(\leq 1 \mathrm{~h} / \mathrm{d})$} & \multicolumn{2}{|c|}{ Middle $(2-3 \mathrm{~h} / \mathrm{d})$} & \multicolumn{2}{|c|}{ High $(\geq 4 \mathrm{~h} / \mathrm{d})$} \\
\hline & Mean & $\mathrm{SE}$ & Mean & $\mathrm{SE}$ & Mean & $\mathrm{SE}$ \\
\hline \multicolumn{7}{|c|}{ Pre-school children (2-5 years) } \\
\hline Boys & $6722 \cdot 5$ & $167 \cdot 1$ & $6959 \cdot 6$ & $177 \cdot 0$ & $7145 \cdot 5$ & $209 \cdot 7$ \\
\hline Girls & $6537 \cdot 9$ & $190 \cdot 1$ & $6606 \cdot 8$ & $108 \cdot 9$ & $6568 \cdot 2$ & $204 \cdot 7$ \\
\hline \multicolumn{7}{|c|}{ School-aged children (6-11 years) } \\
\hline Boys & $8566 \cdot 5$ & $160 \cdot 8$ & $8689 \cdot 7$ & $136 \cdot 8$ & $8927 \cdot 1$ & $267 \cdot 6$ \\
\hline Girls & $7632 \cdot 8$ & $212 \cdot 9$ & $7919 \cdot 1$ & $112 \cdot 8$ & $8016 \cdot 0$ & $273 \cdot 8$ \\
\hline \multicolumn{7}{|c|}{ Adolescents (12-18 years) } \\
\hline Boys & $9914 \cdot 4$ & $248 \cdot 6$ & $9996 \cdot 8$ & $225 \cdot 2$ & $9866 \cdot 2$ & $210 \cdot 1$ \\
\hline Girls & $7801 \cdot 0$ & $166 \cdot 3$ & $8088 \cdot 5$ & $129 \cdot 4$ & $8618 \cdot 2$ & $252 \cdot 2$ \\
\hline \multicolumn{7}{|c|}{ Adults ( $\geq 19$ years) } \\
\hline Men & $9845 \cdot 9$ & $130 \cdot 5$ & $9297 \cdot 2$ & $106 \cdot 8$ & $9372 \cdot 8$ & $173 \cdot 3$ \\
\hline Women & $7540 \cdot 9$ & $120 \cdot 7$ & $7416 \cdot 1$ & $72 \cdot 2$ & $7611 \cdot 8$ & $94 \cdot 0$ \\
\hline
\end{tabular}

TV, television.

Least-squared means adjusted for age, BMI (percentile for all children), physical activity (daily minutes of moderate-to-vigorous physical activity (MVPA) for children aged 12-18 years and adults and weekly times of hard play for children aged 2-11 years), ethnicity and smoking status (adults only).

Different questions were asked to children aged $12-18$ years and adults $v$. children aged $2-11$ years. Older children and adults were asked about minutes of MVPA in the previous month, which was used to calculate weekly minutes of MVPA. Pre-school and school-aged children's parent proxy was asked about the times per week the child engaged in exercise or play enough to sweat and breathe hard.

\section{Discussion}

The present study was unable to show an association between TV viewing and total energy intake in US preschool children, school-aged children, adolescent boys and adult women. However, an association between TV viewing and total energy intake $(\mathrm{kcal} / \mathrm{d})$ was observed among girls aged 12-18 years and men. Adolescent girls in the highest TV viewing category ( $\geq 4 \mathrm{~h} / \mathrm{d}$ ) were estimated to consume $820.5 \mathrm{~kJ}$ (196 kcal) more energy daily than adolescent girls in the lowest TV viewing category $(\leq 1 \mathrm{~h} / \mathrm{d}$ ). These findings are similar to those reported in previous studies that report total energy intake $(\mathrm{kcal} / \mathrm{d})^{(24,51-53)}$ but conflict with others ${ }^{(47,54-57)}$. Men in the middle $(2-3 \mathrm{~h} / \mathrm{d})$ and high $(\geq 4 \mathrm{~h} / \mathrm{d}) \mathrm{TV}$ viewing categories were estimated to consume $464 \cdot 7-473 \cdot 0 \mathrm{~kJ}$ (111-131 kcal) less energy per day compared with men in the lowest TV viewing category $(\leq 1 \mathrm{~h} / \mathrm{d})$. This is in contrast with previous reports of a positive $^{(47)}$ or null ${ }^{(51)}$ relationship. It is worth noting that all age and sex groups reported dietary intake within the recommended ranges of $6694-10042 \mathrm{~kJ}(1600-2400 \mathrm{kcal})$ for women and 8368-12552 kJ (2000-3000 kcal) for men; albeit energy intake needs for weight maintenance depend on the age, sex, size and physical activity of the individual $^{(58)}$. Dietary intake and food consumption patterns have been previously reported in a number of studies and are summarized in a review published recently ${ }^{(40)}$. This review states that while the majority of studies show a positive association between TV viewing and diet, not all studies agree $^{(40)}$. These discrepancies can likely be attributed to differences in methodology of dietary quality or intake, characteristics of the sample and the complicated nature of the relationship between diet, TV viewing and adiposity.

Measurements of dietary quality have been defined through various methods including but not limited to amount of snacking, fruit, vegetable, fast food, sugarsweetened beverage consumption, total energy intake, FFQ, behavioural questionnaires and $24 \mathrm{~h}$ recalls. The current study utilizes data obtained from two $24 \mathrm{~h}$ dietary recalls, taken 3 to $10 \mathrm{~d}$ apart by a trained interviewer using the automated multiple-pass method to calculate an average of total energy intake. For children under the age of 11 years, proxy respondents assisted or completed the interview on behalf of the child. This methodology was used in a previous study by Bowman ${ }^{(47)}$ using the USDA's Continuing Survey of Food Intakes by Individuals 1994-1996, a nationally representative sample of Americans. Bowman observed that TV viewing was positively associated with energy intake. Men and women who watched $>2 \mathrm{~h}$ TV/d consumed $573.5 \mathrm{~kJ}$ (137 kcal) more energy daily than adults who watched $<1 \mathrm{~h} / \mathrm{d}^{(47)}$. Bowman's results, with nearly identical methodology of data collection, are incongruent with the current findings. Differences may be attributed to differences in analyses; Bowman did not stratify by sex while our analysis does.

In a study that included children and examined the association between total energy intake using similar methodology of dietary recall, Rosenberg et al. ${ }^{(53)}$ found no association between TV viewing and energy intake. Congruent with our findings, Crespo et al. ${ }^{(24)}$ reported an association only in girls such that those viewing $>5 \mathrm{~h} \mathrm{TV} / \mathrm{d}$ consumed $732.6 \mathrm{~kJ}$ ( $175 \mathrm{kcal})$ more energy daily compared with those girls viewing TV for $\leq 1 \mathrm{~h} / \mathrm{d}$. Studies that used FFQ to measure total energy intake consistently showed increasing hours of TV viewing was associated with higher total energy intake $(205 \cdot 1-699 \cdot 1 \mathrm{~kJ} / \mathrm{d}(49-167 \mathrm{kcal} / \mathrm{d}))$ in children ranging from 3 to 12 years of age ${ }^{(54-56)}$. Energy intake calculated from food frequencies could be different from that in a food recall since $\mathrm{kJ} / \mathrm{d}$ are determined based on reported patterns of food intake in the food frequency rather than precisely what was 
Table 3 Relationship between TV viewing and energy intake by age and gender groups, 2003-2006 National Health and Nutrition Examination Survey

\begin{tabular}{|c|c|c|c|c|c|c|}
\hline & \multicolumn{3}{|c|}{ Adjusted model without physical activity } & \multicolumn{3}{|c|}{ Adjusted model with physical activity } \\
\hline & Parameter estimate & $\mathrm{SE}$ & $P$ value & Parameter estimate & SE & $P$ value \\
\hline \multicolumn{7}{|c|}{ Pre-school children (2-5 years) } \\
\hline \multicolumn{7}{|l|}{ Boys } \\
\hline \multicolumn{7}{|l|}{ TV } \\
\hline $\operatorname{Low}(\leq 1 \mathrm{~h} / \mathrm{d})$ & Ref. & & & Ref. & & \\
\hline Middle $(2-3 \mathrm{~h} / \mathrm{d})$ & $56 \cdot 6$ & $49 \cdot 4$ & 0.26 & $56 \cdot 7$ & $47 \cdot 9$ & 0.25 \\
\hline High $(\geq 4 \mathrm{~h} / \mathrm{d})$ & $95 \cdot 2$ & $63 \cdot 5$ & $0 \cdot 14$ & $101 \cdot 0$ & $64 \cdot 8$ & $0 \cdot 13$ \\
\hline \multicolumn{7}{|l|}{ Girls } \\
\hline \multicolumn{7}{|l|}{ TV } \\
\hline $\operatorname{Low}(\leq 1 \mathrm{~h} / \mathrm{d})$ & Ref. & & & Ref. & & \\
\hline Middle $(2-3 \mathrm{~h} / \mathrm{d})$ & $16 \cdot 6$ & $39 \cdot 7$ & 0.68 & $16 \cdot 5$ & $40 \cdot 4$ & 0.69 \\
\hline High $(\geq 4 \mathrm{~h} / \mathrm{d})$ & $7 \cdot 1$ & $60 \cdot 5$ & 0.91 & $7 \cdot 2$ & $60 \cdot 3$ & 0.90 \\
\hline \multicolumn{7}{|c|}{ School-aged children (6-11 years) } \\
\hline \multirow{2}{*}{\multicolumn{7}{|c|}{$\begin{array}{l}\text { Boys } \\
\text { TV }\end{array}$}} \\
\hline & & & & & & \\
\hline \multicolumn{7}{|l|}{$\begin{array}{l}\text { TV } \\
\text { Low }(\leq 1 \mathrm{~h} / \mathrm{d})\end{array}$} \\
\hline Middle $(2-3 \mathrm{~h} / \mathrm{d})$ & $31 \cdot 1$ & $46 \cdot 4$ & 0.51 & $29 \cdot 4$ & $46 \cdot 7$ & 0.53 \\
\hline High $(\geq 4 \mathrm{~h} / \mathrm{d})$ & $85 \cdot 8$ & $73 \cdot 0$ & 0.25 & $86 \cdot 1$ & $73 \cdot 6$ & 0.25 \\
\hline \multicolumn{7}{|l|}{ Girls } \\
\hline \multicolumn{7}{|l|}{ TV } \\
\hline $\operatorname{Low}(\leq 1 \mathrm{~h} / \mathrm{d})$ & Ref. & & & Ref. & & \\
\hline Middle $(2-3 \mathrm{~h} / \mathrm{d})$ & $67 \cdot 9$ & $57 \cdot 2$ & 0.24 & $68 \cdot 4$ & $57 \cdot 2$ & 0.24 \\
\hline High $(\geq 4 \mathrm{~h} / \mathrm{d})$ & $91 \cdot 5$ & $93 \cdot 7$ & 0.34 & $91 \cdot 6$ & $94 \cdot 0$ & 0.34 \\
\hline \multicolumn{7}{|l|}{ Adolescent (12-18 years) } \\
\hline \multirow{2}{*}{\multicolumn{7}{|c|}{$\begin{array}{c}\text { Boys } \\
\text { TV }\end{array}$}} \\
\hline & & & & & & \\
\hline $\operatorname{Low}(\leq 1 \mathrm{~h} / \mathrm{d})$ & Ref. & & & Ref. & & \\
\hline Middle $(2-3 \mathrm{~h} / \mathrm{d})$ & $18 \cdot 9$ & $73 \cdot 4$ & 0.80 & $19 \cdot 7$ & $73 \cdot 6$ & 0.79 \\
\hline High $(\geq 4 \mathrm{~h} / \mathrm{d})$ & $-17 \cdot 2$ & $77 \cdot 2$ & 0.83 & $-11 \cdot 5$ & $80 \cdot 8$ & 0.89 \\
\hline \multicolumn{7}{|l|}{ Girls } \\
\hline \multicolumn{7}{|l|}{ TV } \\
\hline Low $(\leq 1 \mathrm{~h} / \mathrm{d})$ & Ref. & & & Ref. & & \\
\hline Middle $(2-3 \mathrm{~h} / \mathrm{d})$ & $69 \cdot 0$ & $52 \cdot 8$ & 0.21 & $68 \cdot 7$ & $52 \cdot 1$ & $0 \cdot 19$ \\
\hline High $(\geq 4 \mathrm{~h} / \mathrm{d})$ & $196 \cdot 3$ & $87 \cdot 2$ & 0.03 & $195 \cdot 2$ & $85 \cdot 8$ & 0.03 \\
\hline \multicolumn{7}{|l|}{ Adults ( $\geq 19$ years) } \\
\hline \multicolumn{7}{|l|}{ Men } \\
\hline \multicolumn{7}{|l|}{ TV } \\
\hline $\operatorname{Low}(\leq 1 \mathrm{~h} / \mathrm{d})$ & Ref. & & & Ref. & & \\
\hline Middle $(2-3 \mathrm{~h} / \mathrm{d})$ & $-130 \cdot 7$ & 30.5 & 0.0002 & $-131 \cdot 1$ & 30.5 & 0.0002 \\
\hline High $(\geq 4 \mathrm{~h} / \mathrm{d})$ & -110.9 & $44 \cdot 2$ & 0.02 & $-113 \cdot 0$ & $44 \cdot 6$ & 0.02 \\
\hline \multicolumn{7}{|l|}{ Women } \\
\hline \multicolumn{7}{|l|}{ TV } \\
\hline Low $(\leq 1 \mathrm{~h} / \mathrm{d})$ & Ref. & & & Ref. & & \\
\hline Middle $(2-3 \mathrm{~h} / \mathrm{d})$ & $-29 \cdot 4$ & $27 \cdot 5$ & 0.29 & $-29 \cdot 8$ & $27 \cdot 5$ & 0.28 \\
\hline High $(\geq 4 \mathrm{~h} / \mathrm{d})$ & $17 \cdot 4$ & $34 \cdot 1$ & $0 \cdot 61$ & $16 \cdot 9$ & $34 \cdot 2$ & 0.62 \\
\hline
\end{tabular}

TV, television; Ref., referent category.

Different questions were asked to children aged 12-18 years and adults $v$. children aged 2-11 years. Adolescents and adults were asked about minutes of moderate-to-vigorous physical activity (MVPA) in the previous month, which was used to calculate weekly minutes of MVPA. Pre-school and school-aged children's parent proxy was asked about the times per week the child engaged in exercise or play enough to sweat and breathe hard.

The model without physical activity was adjusted for BMI (percentile for all children), age and ethnicity. The model with physical activity included all previously listed covariates and either minutes of MVPA (children 12-18 years and adults) or times per week of hard play (children aged 2-11 years).

Analyses were conducted with average total kcal rather than $\mathrm{kJ}$ to prevent extremely large parameter estimates.

Bold indicates significance $(P<0.05)$.

eaten on the day prior to the recall. It is noteworthy that two of those studies noting an increase in energy intake (as measured by food frequency) and TV viewing ${ }^{(55,56)}$ were from the same Planet Health Study and thereby the same sample of children. Interestingly, a single study using five consecutive days of a weighed food record showed no associated between energy intake and TV viewing, although it was only in sixty adolescents ${ }^{(52)}$.

The present study was only able to demonstrate a positive association between total energy intake (kcal/d) and TV viewing among adolescent girls. The reason why adolescent girls may be at greater risk for higher energy intake with TV viewing is not entirely clear. Boys have consistently been reported to engage in higher volumes of screen-based activities ${ }^{(6-8)}$ and a higher proportion of boys were found to exceed the American Academy of Pediatrics' TV viewing recommendation of $<2 \mathrm{~h} / \mathrm{d}^{(59)}$. Pearson and Biddle's ${ }^{(40)}$ review did conclude that there is a trend towards more consistent relationships between females regarding TV viewing and dietary quality than 
in males. Differences in social and occupational roles between men and women have also been proposed as reasons to explain this relationship observed in women such that the interaction between TV viewing, fast-food eating and weight control are different between genders ${ }^{(51)}$.

Additionally, the results of the present study suggest a negative association between TV viewing and energy intake in men. As noted in the review by Pearson and Biddle $^{(40)}$, no previous studies in men have reported a negative association between TV viewing and energy intake, although two reported no association ${ }^{(51,57)}$. A laboratory-based study found that adult participants consumed more food when given a meal while watching $\mathrm{TV}^{(60)}$. A study conducted in children $12-16$ years of age that decreased sedentary behaviour by $25-50 \%$ for three weeks reported a decrease in energy intake during that time $^{(61)}$. However, when the reverse experiment was performed (increased sedentary behaviours by $25-50 \%$ for three weeks) there was not a concomitant increase in energy intake ${ }^{(61)}$. The interventions were counterbalanced in the order received by participants to prevent any timing effect. It is clear that the relationship between TV viewing and dietary patterns is complex. When total energy intake, which would most directly be associated with overweight and obesity, is the dietary outcome of interest, the findings are mixed.

The findings of the current study indicate TV viewing is not positively associated with energy intake, except in 12-18-year-old girls. Additionally, TV viewing is negatively associated with energy intake in men. These findings should be interpreted in light of the study's strengths and weaknesses. The study had a large sample size and utilized data obtained from a nationally representative sample of US men, women and children. Additionally, both $24 \mathrm{~h}$ dietary recalls were administered by highly trained NHANES interviewers with the assistance of the automated multiple-pass method. These data allowed us to estimate the average total energy $(\mathrm{kcal} / \mathrm{d})$ intake for all subjects. Furthermore, participants were sent home with food models and portions size aids to enhance the accuracy of the telephone recall interview. However, limitations in the accuracy, honesty and social desirability of intake in dietary recall methodology are always a concern $^{(62-64)}$. It is also worth noting that different interview methodologies (i.e. in-person $v$. telephone) were used for the day 1 recall and the day 2 recall. There were no major differences in the association between TV viewing and energy intake between day 1 , day 2 and the average with the exception of adolescent girls. The day 2 and averaged analyses were similar while day 1 showed a similar pattern; however statistical significance was not reached. Usage of proxy report and assistance is an additional limitation since proxies may not know exactly what was consumed on the day prior to the interview. TV viewing is also self- or proxy-reported in a categorical fashion. Observation of TV viewing or electronic TV monitors is a more accurate method to measure TV viewing. Additionally, reporting the continuous number of hours of TV viewing would allow greater flexibility and precision in analysis.

\section{Conclusions}

In summary, TV viewing in adult women and children in the 2003-2006 NHANES was not associated with energy intake, with the exception of adolescent girls and adult men. Previous evidence generally shows that higher TV viewing is associated with poorer dietary quality and higher energy intake, although not all studies support this relationship ${ }^{(40)}$. It is recommended that future studies explore the relationship of TV viewing and energy intake in children and adults due to the discrepant research findings. This is particularly relevant to understand the differences between males and females regarding TV viewing and energy intake. It is likely that TV viewing is associated with diet ${ }^{(40)}$; however, it may be due to dietary patterns, such as fruit, vegetable and fast-food consumption, than energy intake per se. Another measurement issue future studies may explore would be to ascertain the precision with which people can recall the quantity of food they consume while viewing TV. A recent opinion article addresses the hypothesis that eating while viewing TV leads to distraction ${ }^{(65)}$ which could potentially impact energy intake as well as recall of food consumed. Viewing TV while eating may lead to underreporting of energy intake if portion sizes are underestimated or not recalled. There is some evidence, at least in adults ${ }^{(66,67)}$, that watching TV while eating impairs memory of food consumed during the meal. Therefore, examination of type of foods consumed such as fast food, energy-dense foods or fruit and vegetables may provide better explanations of food patterns $v .24 \mathrm{~h}$ recalls. This may be particularly true because of social desirability leading to under-reporting of intake, compounded with inability to accurately recall the quantity of food consumed while TV viewing, leading to further underreporting. New technologies that can be used with food reporting such as digital photography pre and post meal could be another avenue to more accurately explore the relationship of energy intake and TV viewing. The dearth of research studying this phenomenon, especially in children, warrants further studies. Other areas for future research should include examination of the hypothesis related to precisely how and why TV viewing is associated with overweight and obesity. The complexity of these relationships is clear and well-designed studies are needed to gain deeper understanding and evidence for or against each hypothesis. Future research should also examine longitudinal and interventions where TV viewing is manipulated to discern if this relationship is amenable to change. 


\section{Acknowledgements}

This research received no specific grant from any funding agency in the public, commercial or not-for-profit sectors. There are no conflicts of interest. S.B.S. and S.T.B. designed the research; S.B.S., L.B. and C.R. analysed the data; S.B.S., S.T.B., L.B., C.R. and M.L. wrote the paper; S.B.S. had primary responsibility for final content. All authors read and approved the final manuscript.

\section{References}

1. Pate RR, O'Neill JR \& Lobelo F (2008) The evolving definition of 'sedentary'. Exerc Sport Sci Rev 36, 173-178.

2. Salmon J, Dunstan D \& Owen N (2008) Should we be concerned about children spending extended periods of time in sedentary pursuits even among the highly active? Int J Pediatr Obes 3, 66-68.

3. Spanier PA, Marshall SJ \& Faulkner GE (2006) Tackling the obesity pandemic: a call for sedentary behaviour research. Can J Public Health 97, 255-257.

4. Owen N, Healy GN, Matthews CE et al. (2010) Too much sitting: the population health science of sedentary behavior. Exerc Sport Sci Rev 38, 105-113.

5. Healy GN \& Owen N (2010) Sedentary behaviour and biomarkers of cardiometabolic health risk in adolescents: an emerging scientific and public health issue. Rev Esp Cardiol 63, 261-264.

6. Sisson SB, Church TS, Martin CK et al. (2009) Profiles of sedentary behavior in children and adolescents: The US National Health and Nutrition Examination Survey, 2001-2006. Int J Pediatr Obes 4, 353-359.

7. Gorely T, Biddle SJ, Marshall SJ et al. (2009) The prevalence of leisure time sedentary behaviour and physical activity in adolescent boys: an ecological momentary assessment approach. Int J Pediatr Obes 4, 289-298.

8. Gorely T, Marshall SJ, Biddle SJ et al. (2007) The prevalence of leisure time sedentary behaviour and physical activity in adolescent girls: an ecological momentary assessment approach. Int J Pediatr Obes 2, 227-234.

9. Rideout VJ, Foehr UG \& Roberts DF (2010) Generation M2: Media in the Lives of 8-to 18-Year Olds. Menlo Park, CA: Henry J. Kaiser Family Foundation.

10. Sisson SB, Broyles ST, Baker BL et al. (2010) Screen time, physical activity, and overweight in US youth: National Survey of Children's Health 2003. J Adolesc Health 47, 309-311.

11. US Department of Labor (2011) American Time Use Survey: Leisure Time on an Average Day. http://www.bls.gov/tus/ charts/leisure.htm (accessed June 2011).

12. Clark BK, Sugiyama T, Healy GN et al. (2009) Validity and reliability of measures of television viewing time and other non-occupational sedentary behaviour of adults: a review. Obes Rev 10, 7-16.

13. Katzmarzyk PT, Church TS, Craig CL et al. (2009) Sitting time and mortality from all causes, cardiovascular disease, and cancer. Med Sci Sports Exerc 41, 998-1005.

14. Dunstan DW, Barr EL, Healy GN et al. (2010) Television viewing time and mortality: the Australian Diabetes, Obesity and Lifestyle Study (AusDiab). Circulation 121, 384-391.

15. Healy GN, Dunstan DW, Salmon J et al. (2008) Television time and continuous metabolic risk in physically active adults. Med Sci Sports Exerc 40, 639-645.

16. Healy GN, Matthews CE, Dunstan DW et al. (2011) Sedentary time and cardio-metabolic biomarkers in US adults: NHANES 2003-06. Eur Heart J 32, 590-597.
17. Hu FB, Leitzmann MF, Stampfer MJ et al. (2001) Physical activity and television watching in relation to risk for type 2 diabetes mellitus in men. Arch Intern Med 161, 1542-1548.

18. Hu FB, Li TY, Colditz GA et al. (2003) Television watching and other sedentary behaviors in relation to risk of obesity and type 2 diabetes mellitus in women. JAMA 289, $1785-1791$.

19. Jakes RW, Day NE, Khaw KT et al. (2003) Television viewing and low participation in vigorous recreation are independently associated with obesity and markers of cardiovascular disease risk: EPIC-Norfolk population-based study. Eur J Clin Nutr 57, 1089-1096.

20. Sardinha LB, Andersen LB, Anderssen SA et al. (2008) Objectively measured time spent sedentary is associated with insulin resistance independent of overall and central body fat in 9- to 10-year-old Portuguese children. Diabetes Care 31, 569-575.

21. Martinez-Gomez D, Eisenmann JC, Gomez-Martinez S et al. (2010) Sedentary behavior, adiposity and cardiovascular risk factors in adolescents. The AFINOS study. Rev Esp Cardiol 63, 277-285.

22. Rey-Lopez JP, Vicente-Rodriguez G, Biosca M et al. (2008) Sedentary behaviour and obesity development in children and adolescents. Nutr Metab Cardiovasc Dis 18, 242-251.

23. Marshall SJ, Biddle SJ, Gorely T et al. (2004) Relationships between media use, body fatness and physical activity in children and youth: a meta-analysis. Int J Obes Relat Metab Disord 28, 1238-1246.

24. Crespo CJ, Smit E, Troiano RP et al. (2001) Television watching, energy intake, and obesity in US children: results from the third National Health and Nutrition Examination Survey, 1988-1994. Arch Pediatr Adolesc Med 155, 360-365.

25. Eisenmann JC, Bartee RT, Smith DT et al. (2008) Combined influence of physical activity and television viewing on the risk of overweight in US youth. Int J Obes (Lond) 32, 613-618.

26. Atkin AJ, Gorely T, Biddle SJ et al. (2008) Critical hours: physical activity and sedentary behavior of adolescents after school. Pediatr Exerc Sci 20, 446-456.

27. Ekelund U, Brage S, Froberg K et al. (2006) TV viewing and physical activity are independently associated with metabolic risk in children: the European Youth Heart Study. PLoS Med 3, e488.

28. Jackson DM, Djafarian K, Stewart J et al. (2009) Increased television viewing is associated with elevated body fatness but not with lower total energy expenditure in children. Am J Clin Nutr 89, 1031-1036.

29. Robinson TN (1999) Reducing children's television viewing to prevent obesity: a randomized controlled trial. JAMA 282, 1561-1567.

30. Epstein LH, Roemmich JN, Robinson JL et al. (2008) A randomized trial of the effects of reducing television viewing and computer use on body mass index in young children. Arch Pediatr Adolesc Med 162, 239-245.

31. Cooper TV, Klesges LM, Debon M et al. (2006) An assessment of obese and non obese girls' metabolic rate during television viewing, reading, and resting. Eating Behav 7, 105-114.

32. Klesges RC, Shelton ML \& Klesges LM (1993) Effects of television on metabolic rate: potential implications for childhood obesity. Pediatrics 91, 281-286.

33. Swinburn B \& Shelly A (2008) Effects of TV time and other sedentary pursuits. Int J Obes (Lond) 32, Suppl. 7, S132-S136.

34. Aktas Arnas Y (2006) The effects of television food advertisement on children's food purchasing requests. Pediatr Int 48, 138-145.

35. Vader AM, Walters ST, Harris TR et al. (2009) Television viewing and snacking behaviors of fourth- and eighthgrade schoolchildren in Texas. Prev Chronic Dis 6, A89. 
36. Chamberlain LJ, Wang Y \& Robinson TN (2006) Does children's screen time predict requests for advertised products? Cross-sectional and prospective analyses. Arch Pediatr Adolesc Med 160, 363-368.

37. Parvanta SA, Brown JD, Du S et al. (2010) Television use and snacking behaviors among children and adolescents in China. J Adolesc Health 46, 339-345.

38. Temple JL, Giacomelli AM, Kent KM et al. (2007) Television watching increases motivated responding for food and energy intake in children. Am J Clin Nutr 85, 355-361.

39. Blass EM, Anderson DR, Kirkorian HL et al. (2006) On the road to obesity: television viewing increases intake of highdensity foods. Physiol Behav 88, 597-604.

40. Pearson N \& Biddle SJ (2011) Sedentary behavior and dietary intake in children, adolescents, and adults a systematic review. Am J Prev Med 41, 178-188.

41. Swinburn B, Sacks G \& Ravussin E (2009) Increased food energy supply is more than sufficient to explain the US epidemic of obesity. Am J Clin Nutr 90, 1453-1456.

42. Swinburn BA, Sacks G, Lo SK et al. (2009) Estimating the changes in energy flux that characterize the rise in obesity prevalence. Am J Clin Nutr 89, 1723-1728.

43. Ogden CL, Carroll MD, Curtin LR et al. (2006) Prevalence of overweight and obesity in the United States, 1999-2004. JAMA 295, 1549-1555.

44. Thorpe KE (2009) The Future Costs of Obesity: National and State Estimate of the Impact of Obesity on Direct Health Care Expenses. Minnetonka, MN: United Health Foundation, American Public Health Association \& Partnership for Prevention.

45. World Health Organization (1997) Obesity: Preventing and Managing the Global Epidemic. Report of a WHO Consultation on Obesity. WHO Technical Report Series no. 894. Geneva: WHO.

46. Kuczmarski RJ \& Flegal KM (2000) Criteria for definition of overweight in transition: background and recommendations for the United States. Am J Clin Nutr 72, 1074-1081.

47. Bowman SA (2006) Television-viewing characteristics of adults: correlations to eating practices and overweight and health status. Prev Chronic Dis 3, A38.

48. Centers for Disease Control and Prevention (2006) National Health And Nutrition Examination Survey MEC In-Person Dietary Interviews Procedures Manual. http://www.cdc. gov/nchs/data/nhanes/nhanes_05_06/DIETARY_MEC.pdf (accessed April 2011).

49. Centers for Disease Control and Prevention (2005) National Health And Nutrition Examination Survey Phone FollowUp Dietary Interviewer Procedure Manual. http://www. cdc.gov/nchs/data/nhanes/nhanes_05_06/DIETARY_PFU.pdf (accessed April 2011).

50. Thompson FE \& Byers $\mathrm{T}$ (1994) Dietary assessment resource manual. J Nutr 124, 11 Suppl., 2245S-2317S.

51. Jeffery RW \& French SA (1998) Epidemic obesity in the United States: are fast foods and television viewing contributing? Am J Public Health 88, 277-280.

52. Ortega RM, Andres P, Requejo AM et al. (1996) Influence of the time spend watching television on the dietary habits, energy intake and nutrient intake of a group of Spanish adolescents. Nutr Res 16, 1469-1470.

53. Rosenberg DE, Norman GJ, Sallis JF et al. (2007) Covariation of adolescent physical activity and dietary behaviors over 12 months. J Adolesc Health 41, 472-478.

54. Miller SA, Taveras EM, Rifas-Shiman SL et al. (2008) Association between television viewing and poor diet quality in young children. Int J Pediatr Obes 3, 168-176.

55. Sonneville KR \& Gortmaker SL (2008) Total energy intake, adolescent discretionary behaviors and the energy gap. Int J Obes (Lond) 32, Suppl. 6, S19-S27.

56. Wiecha JL, Peterson KE, Ludwig DS et al. (2006) When children eat what they watch: impact of television viewing on dietary intake in youth. Arch Pediatr Adolesc Med 160, 436-442.

57. Gore SA, Foster JA, DiLillo VG et al. (2003) Television viewing and snacking. Eating Behav 4, 399-405.

58. VanHorn LV, Fukagawa NK, Achterberg C et al. (2010) Report of the Dietary Guideliens Advisory Committee on the Dietary Guidelines for Americans, 2010. Washington, DC: Secretary of Agriculture and the Secretary of Health and Human Services, US Department of Agriculture.

59. Sisson SB, Broyles ST, Baker B et al. (2011) Television, reading, and computer time: correlates of leisure time sedentary behavior and relationship with obesity in children in the US. J Phys Act Health 8, Suppl. 2, S188-S197.

60. Bellisle F, Dalix AM \& Slama G (2004) Non food-related environmental stimuli induce increased meal intake in healthy women: comparison of television viewing versus listening to a recorded story in laboratory settings. Appetite 43, 175-180.

61. Epstein LH, Roemmich JN, Paluch RA et al. (2005) Influence of changes in sedentary behavior on energy and macronutrient intake in youth. Am J Clin Nutr 81, 361-366.

62. Hebert JR, Hurley TG, Peterson KE et al. (2008) Social desirability trait influences on self-reported dietary measures among diverse participants in a multicenter multiple risk factor trial. J Nutr 138, issue 1, 226S-234S.

63. Hebert JR, Ma Y, Clemow L et al. (1997) Gender differences in social desirability and social approval bias in dietary selfreport. Am J Epidemiol 146, 1046-1055.

64. Miller TM, Abdel-Maksoud MF, Crane LA et al. (2008) Effects of social approval bias on self-reported fruit and vegetable consumption: a randomized controlled trial. Nutr $J 7,18$.

65. de Graaf C \& Kok FJ (2010) Slow food, fast food and the control of food intake. Nat Rev Endocrinol 6, 290-293.

66. Oldham-Cooper RE, Hardman CA, Nicoll CE et al. (2011) Playing a computer game during lunch affects fullness, memory for lunch, and later snack intake. Am J Clin Nutr 93, 308-313.

67. Higgs S \& Woodward M (2009) Television watching during lunch increases afternoon snack intake of young women. Appetite 52, 39-43. 